\title{
Analisa Pengaruh Variasi Kecepatan Pada Mobile Station Sistem Komunikasi Mobile to Mobile Rician Fading
}

\author{
Zulaeha Mabud \\ Program Studi Teknik Elektro \\ Fakultas Teknik, Universitas Khairun \\ Email : riset.fte@gmail.com
}

\begin{abstract}
Abstrak - Dalam suatu sistem komunikasi tidak menutup kemungkinan transmiter dan receiver bergerak pada lingkungan multipath fading dengan kondisi diantara transmitter dan receiver tersebut terdapat komponen LOS. Pada makalah ini akan dibahas mengenai sistem komunikasi kooperatif dengan kanal mobile-to-mobile Rician fading. Pada model sistem tersebut terdapat komponen Line-of-Sight (LOS) yang digabungkan dengan pergerakan relatif antara transmitter dan receiver ke dalam model scattering "correlated double-ring". Untuk mengetahui unjuk kerjanya, maka sistem komunikasi dengan model mobile-to-mobile Rician fading dengan variasi kecepatan, disimpulkan dengan kecepatan $40 \mathrm{~km} / \mathrm{jam}$, nilai BER $10^{-4}$ sudah bisa dicapai ketika Eb/No bernilai $16 \mathrm{~dB}$ sedangkan pada kecepatan $90 \mathrm{~km} / \mathrm{jam}$ nilai BER $10^{-4}$ baru bisa dicapai pada saat $\mathrm{Eb} / \mathrm{No}$ bernilai $16.5 \mathrm{~dB}$ dan pada kecepatan $140 \mathrm{~km} /$ jam nilai BER $10^{-4}$ dicapai pada saat $\mathrm{Eb} /$ No bernilai 17.5 dB. Dari analisa pada hasil simulasi diketahui bahwa sistem dapat bekerja lebih baik dengan kondisi kecepatan yang rendah yaitu $40 \mathrm{~km} / \mathrm{jam}$ bila dibandingkan dengan kecepatan $90 \mathrm{~km} / \mathrm{jam}$ atau $140 \mathrm{~km} / \mathrm{jam}$.
\end{abstract}

Kata kunci : Sistem komunikasi koperatif, Mobile-to-mobile, line-of-sight (LOS), Rician fading.

\section{PENDAHULUAN}

Beberapa tahun terakhir, multiple antena pemancar dan receiver menarik perhatian pada bidang komunikasi wireless. Multiple antena berfungsi untuk memperbaiki throughput dengan cara yang praktis dan efisien yaitu melalui perencanaan space-time code. Salah satu cara yang tepat untuk menghasilkan keadaan di atas adalah melalui penggunaan sistem komunikasi kooperatif. Pada kenyataanya, di dalam sistem kooperatif terdapat komunikasi antar user yang dapat bergerak (mobile) yang disebut dengan komunikasi kooperatif mobile-to-mobile. Tidak seperti sistem radio seluler yang traditional dimana base station tidak dapat bergerak dan hanya terminal mobile yang dapat bergerak, transmitter dan receiver pada sistem komunikasi mobile-to-mobile bergerak secara simultan. Oleh karena itu, banyak model kanal yang dikembangkan untuk sistem radio seluler konvensional yang mungkin tidak dapat diterapkan secara langsung pada sistem komunikasi kooperatif mobileto-mobile. Kemudian dikembangkanlah model komunikasi mobile-to-mobile.
Pada [1], telah dikembangkan unjuk kerja secara teoritis dari kanal mobile-to-mobile. Pada [2], sebuah metode discrete line spectrum diperkenalkan untuk model kanal komunikasi mobile-to-mobile. Pada [3], menunjukkan bahwa metode discrete line spectrum dapat bekerja secara baik hanya pada kondisi bentuk gelombang yang berdurasi pendek. Variasi dari penjumlahan sinusoida diusulkan untuk model kanal mobile-to-mobile Rayleigh fading. Metode sumof-sinusoids pada [3] tersebut lebih akurat dibandingkan dengan metode discrete line spectrum.

Pada proses pentransmisian data, tidak menutup kemungkinan diantara transmitter dan receiver terdapat komoonen LOS. Dengan kondisi tersebut maka dibuatlah kanal mobile-to-mobile Rician fading. Model kanal tersebut merupakan perluasan model double ring scattering pada [3], dimana dua ring yang independent digunakan untuk pemodelan pengaruh yang mengelilingi transmitter dan receiver. Komponen LOS menyebabkan korelasi yang tinggi antara transmitter dan receiver. Oleh karena itu model scattering yang digunakan dinamakan dengan "correlated double ring".

Untuk mengetahui kinerja sistem komunikasi kooperatif dengan kanal mobile-to-mobile Rician fading ini, maka hasil simulasi berupa BER dari sistem tersebut akan dibandingkan dengan nilai BER dari hasil simulasi sistem komunikasi kooperatif dengan kanal Rayleigh fading.

\section{PEMODELAN SISTEM}

Bab ini menjelaskan pemodelan sistem komunikasi kooperatif dengan kanal mobile-to-mobile Rician fading. Dinamakan mobile-to-mobile dikarenakan user dan relay berupa mobile station yang dapat bergerak dengan kecepatan tertentu. Pada sistem ini terdapat komponen LOS yang menyebabkan korelasi antara transmitter dan receiver. Sehingga digunakan model scattering correlated double ring. Pemodelan sistem komunikasi kooperatif dengan kanal mobile-to-mobile Rician fading dpat dilihat pada gambar 1. 


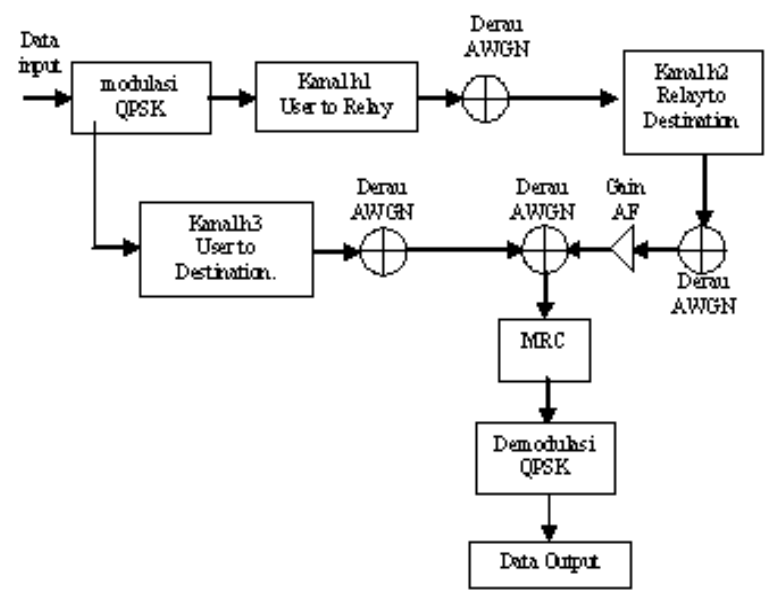

Gambar 1. Pemodelan sistem komunikasi kooperatif dengan kanal m2m Rician fading

Pada awalnya akan dibangkitkan bit informasi sebagai input data biner. Kemudian data tersebut akan dimodulasi QPSK (Quadrature Phase Shift Keying). Data yang termodulasi tersebut akan ditransmisikan melalui tiga kanal yaitu $h_{1}, h_{2}$ dan $h_{3}$. Pada tahap pertama data ditransmisikan oleh user ke relay akan melewati kanal $h_{l}$. Kemudian data yang ditransmisikan tersebut akan terkena derau AWGN. Secara bersamaan data juga akan ditransmisikan oleh user ke destination melalui kanal $h_{3}$. Pada tahap kedua, data yang diterima oleh relay akan dikuatkan terlebih dahulu dengan penguatan AF dan selanjutnya akan diteruskan ke destination melalui kanal $h_{2}$. Data yang ditransmisikan melalui masingmasing kanal tersebut akan terkena derau AWGN. Semua data yang diterima destination, baik yang berasal dari relay maupun user akan dicombining menggunakan MRC untuk mendapatkan kinerja yang paling baik.

\section{A. Sistem Komunikasi Kooperatif}

Sistem komunikasi kooperatif terdiri dari node source, relay dan destination. Informasi dari source dikirimkan ke node relay dan destination. Sinyal yang dikirimkan dari source dan relay bersifat jamak, kemudian sinyal-sinyal tersebut dikombinasikan di destination untuk mendapatkan kinerja yang paling baik. Pada sistem komunikasi kooperatif ini memungkinkan antena tunggal untuk mencapai virtual antena jamak dengan penggunaan secara bersamaan antena dari setiap user.

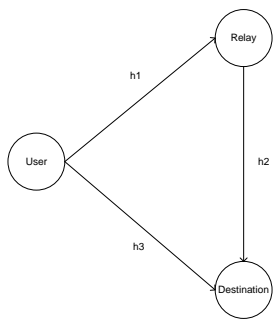

Gambar 2. Sistem komunikasi kooperatif.

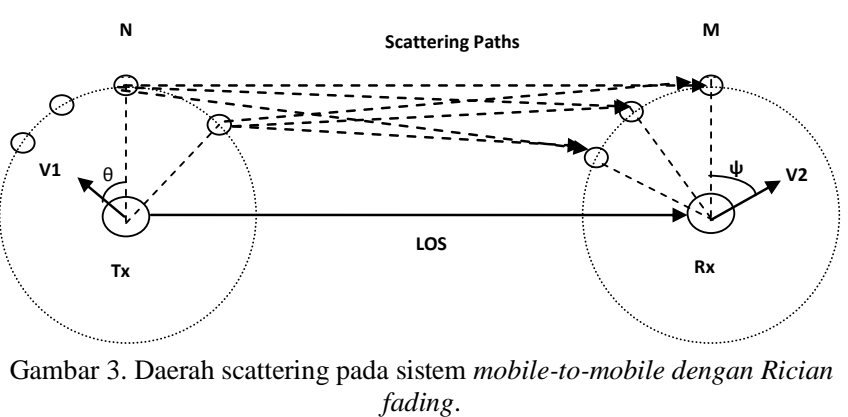

\section{B. Model Scattering “Correlated Double Ring”}

Gambar 3 menunjukkan sistem komunikasi mobile-tomobile dimana transmitter dan receiver bergerak dengan kecepatan $v_{l}$ dan $v_{2}$. Terdapat $N$ dan $M$ scatter mengelilingi transmitter dan receiver. Sedangkan $\theta_{n}$ menunjukkan sudut awal antara $v_{1}$ dan garis scattering, dengan $n=1,2, \ldots, N$ dan $\Psi_{m}$ merupakan sudut antara $v_{2}$ dan garis scattering, dimana $m=1,2, \ldots, M$. Komponen LOS menyediakan korelasi yang tinggi antara transmitter dan receiver.

\section{Model Komponen Line-of-Sight (LOS)}

Line-of-sight merupakan komponen yang dimodelkan dengan perumusan matematika khususnya untuk keadaan dimana transmitter dan receiver bergerak.

Gambar 4, $v_{3}$ menunjukkan kecepatan relatif dari transmitter. Pada gambar tersebut, $\theta^{\prime}$ adalah sudut antara $v_{3}$ dan komponen LOS. Kecepatan relatif $v_{3}$ diperoleh dengan menggunakan geometri dan trigonometri sebagai berikut :

$$
v_{3}=\sqrt{\boldsymbol{\phi}_{1} \cos \boldsymbol{Q}_{\text {diff }}-v_{2}{ }^{2}+\boldsymbol{\ell}_{1} \sin \boldsymbol{Q}_{\text {diff }} \boldsymbol{z}^{2}}
$$

$$
\theta^{\prime}=\theta_{\text {send }}+\theta_{31 d i f f}
$$

dan

$$
\theta_{31 \text { diff }}=\cos ^{-1}\left(\frac{v_{1}^{2}+v_{3}^{2}-v_{2}^{2}}{2 v_{1} \cdot v_{3}}\right)
$$

dengan $v_{l}$ dan $v_{2}$ adalah kecepatan dari transmitter dan receiver pada mobile-to-mobile, $\theta_{\text {diff }}$ adalah sudut antara $v_{l}$ dan $v_{2}, \theta_{\text {send }}$ adalah sudut antara $v_{l}$ dan komponen LOS, $\theta_{31 \text { diff }}$ adalah sudut antara $v_{3}$ dan $v_{l}$. Kemudian komponen LOS dapat ditulis,

$$
L O S=\sqrt{K} \exp \left(\ll f_{3} t \cos \boldsymbol{Q}^{\top}+\phi_{0}\right.
$$

dengan $f_{3}$ adalah nilai frekuensi yang diperoleh dari $v_{3} / \lambda$ dan $\phi_{0}$ adalah fasa yang terdistribusi uniform melalui $[-\pi, \pi]$. 


\section{Mobile-to-mobile Kanal Rician fading}

Berdasarkan model scattering "correlated double ring" pada gambar 3, kemudian dibangun model kanal mobile-tomobile dengan komponen LOS.
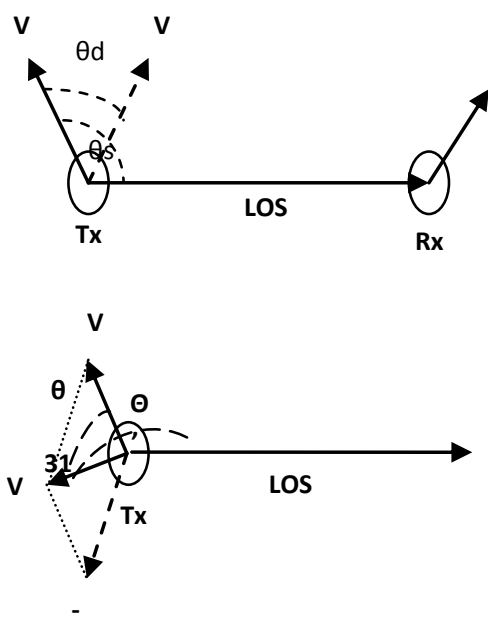

Gambar 4. Menunjukkan parameter $\theta_{\text {send }}, \theta_{\text {diff }}, v 3, \theta_{31 \text { diff }}$ dan $\theta$

\section{E. Rician fading}

Dari (4) dan (5), dapat dituliskan nilai envelope yang diterima oleh model kanal mobile-to-mobile Rician fading sebagai berikut

$$
Z \mathbf{C}=\frac{Y\left(\sqrt { K } \operatorname { e x p } \left(j\left(\pi f_{3} t \cos \boldsymbol{\theta}+\phi_{0}\right)\right.\right.}{\sqrt{1+K}}
$$

dengan $Z$ _ merupakan nilai selubung kompleks dari kanal mobile-to-mobile Rician fading yang mana nilai pembilangnya merupakan penjumlahan dari nilai selubung dari kanal Rayleigh fading dan nilai komponen LOS.

\section{ANALISA HASIL SIMULASI}

Sebelum menunjukkan perbedaan kinerja sistem komunikasi kooperatif dengan kanal mobile-to-mobile Rician fading dan sistem komunikasi kooperatif dengan kanal Rayleigh fading, maka akan dijelaskan beberapa parameter yang digunakan dalam simulasi yang menggunakan bahasa pemrograman matlab 7.3.

\section{A. Parameter Simulasi}

Data input dibangkitkan secara acak sebanyak 100.000 bit. Dengan menggunakan teknik modulasi QPSK. Kanal pada sistem diasumsikan terkena derau AWGN. Kemudian pada sistem dengan kanal mobile-to- mobile Rician fading ini user dan relay dapat bergerak dengan variasi kecepatan dan arah tertentu. Sedangkan sudut scattering pada masingmasing antena dibangkitkan secara acak dan terdistribusi uniform pada $[-\pi, \pi]$. Data diambil dengan melakukan percobaan masing-masing titik pada grafik sebanyak 10 kali.

\section{B. Analisa Hasil Simulasi Sistem Komunikasi M2M Rician fading Berdasarkan Variasi Kecepatan Pada Mobile station}

Gambar 5 merupakan hasil simulasi pada sistem komunikasi kooperatif dengan kanal Mobile-to-mobile Rician fading dengan memberikan nilai kecepatan yang bervariasi pada mobile station dalam hal ini user dan relay. $\mathrm{V}_{1}$ merupakan kecepatan pada user sedangkan $\mathrm{V}_{2}$ adalah kecepatan pada relay. Simulasi ini dilakukan untuk melihat pengaruh nilai kecepatan pada kinerja sistem komunikasi kooperatif dengan kanal mobile-to-mobile Rician fading.

Hasil yang diperoleh menunjukkan bahwa mobile station yang mempunyai kecepatan $40 \mathrm{~km} / \mathrm{jam}$ memiliki unjuk kerja yang lebih baik dibandingkan dengan mobile station yang memiliki kecepatan $90 \mathrm{~km} / \mathrm{jam}$ dan $140 \mathrm{~km} / \mathrm{jam}$. Hal ini ditunjukkan oleh pencapaian nilai BER yang diperoleh dari hasil simulasi. Dimana dengan kecepatan $40 \mathrm{~km} / \mathrm{jam}$, nilai BER $10^{-4}$ sudah bisa dicapai ketika Eb/No bernilai $16 \mathrm{~dB}$ sedangkan pada kecepatan $90 \mathrm{~km} / \mathrm{jam}$ nilai BER $10^{-4}$ baru bisa dicapai pada saat Eb/No bernilai $16.5 \mathrm{~dB}$ dan pada kecepatan $140 \mathrm{~km} / \mathrm{jam}$ nilai BER $10^{-4}$ dicapai pada saat Eb/No bernilai $17.5 \mathrm{~dB}$.

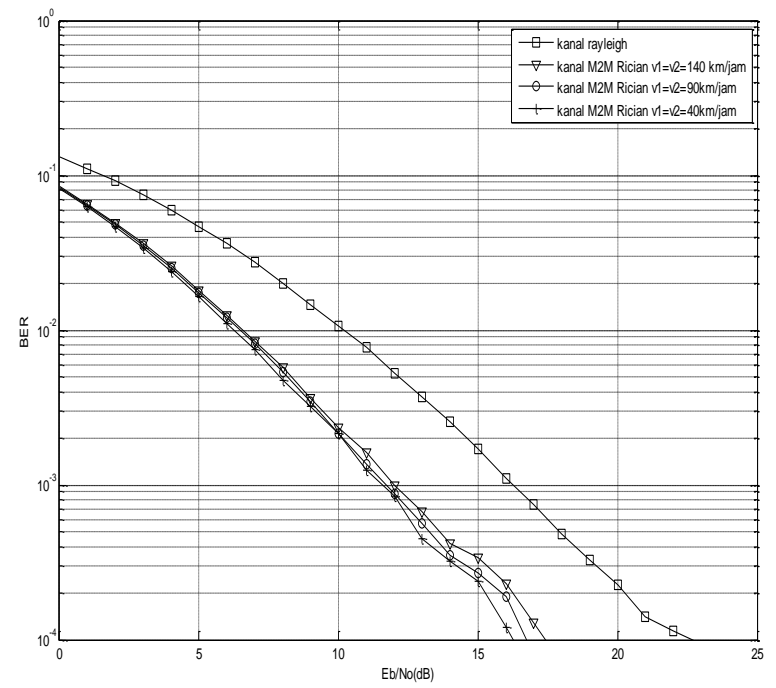

Gambar 5. Grafik BER sistem komunikasi kooperatif dengan kanal Rician fading berdasarkan variasi kecepatan pada mobile station

Dengan menggunakan kecepatan yang berbeda maka dapat dilihat sistem komunikasi kooperatif dengan kanal mobile-to-mobile Rician fading dapat bekerja dengan baik pada kondisi kecepatan rendah atau tinggi. Dari analisa pada hasil simulasi diketahui bahwa sistem dapat bekerja lebih baik dengan kondisi kecepatan yang rendah yaitu 40 km/jam bila dibandingkan dengan kecepatan $90 \mathrm{~km} / \mathrm{jam}$ atau 140 $\mathrm{km} / \mathrm{jam}$. 
Analisa Pengaruh Variasi Kecepatan Pada Mobile Station Sistem Komunikasi Mobile to Mobile Rician Fading

\section{KESIMPULAN}

Sistem komunikasi kooperatif dengan kanal mobile-tomobile Rician fading dengan menggunakan model scattering "correlated double ring" untuk menggolongkan komunikasi mobile-to-mobile dengan kondisi terdapat komponen LOS diantara transmitter dan receiver. Keakuratan dari model kanal tersebut dapat dibuktikan dengan melakukan simulasi untuk mengetahui kinerja sistemnya. Dari hasil simulasi dapat disimpulkan bahwa sistem komunikasi dengan model ini memiliki kinerja sistem yang lebih baik $6 \mathrm{~dB}$ bila dibandingkan dengan sisten komunikasi kooperatif dengan model kanal Rayleigh fading. Hal ini dikarenakan pada sistem dengan kanal Rician fading terdapat komponen LOS. Dengan menggunakan komponen LOS maka proses pentransmisian data dapat dilakukan secara langsung tanpa ada ganngguan yang berupa obstacle yang menyebabkan data tidak dapat diterima oleh receiver secara maksimal.

\section{DAFTAR PUSTAKA}

[1] A. S. Akki and F. Haber, "A statistical model for mobiletomobile land communication channel," IEEE Transactions on Vehicular Technology, vol. VT-35, Feb 1986.

[2] R. Wnag and D. Cox, "Channel modeling for ad hoc mobile wireless networks," IEEE Vehicular Technology Conference, vol. 1, pp. 21-25, May 2002.

[3] C. S. Patel, G. L. St"uber, and T. G. Pratt, "Simulation of rayleigh faded mobile-to-mobile communication channels,'IEEE Vehicular Technology Conference, vol. 1, pp. 163-167, October 2003.

[4] W, Li-Chun., C, Yun-Huai, "A Statistical Mobile-to-mobile Rician fading Channel Model", IEEE, 2005.

[5] T.S. Rappaport, "Wireless Communications Principles and Practice”, Prentice Hall, New Jersey, 1996 